\section{THE TORONTO HOSPITAL} FOR

\section{ADVANCED AND FAR-ADVANCED CASES OF CONSUMPTION.}

By SIR W. H. BROADBENT, M.D., F.R.S., PHYSICIAN IN ORDINARY TO H.M. THE KING.

A smalc hospital to which I was taken by the Treasurer Mr. Herbert Hammond, in the course of the meeting at Toronto, is worthy of special notice. It is the Hospital for Advanced and Far-advanced Cases of Consumption.

I do not know what the death-rate from phthisis is in Canada generally, or in the individual States, but it is sufficiently large to have called for an Association for the Prevention of Consumption, which is doing active work chiefly of an educational character, but also in promoting the erection of sanatoriums.

Tuberculosis in its various forms is often spoken of as a disease of poverty. There is no doubt some relation between poverty and consumption in Canada-poverty relative to the great expense of house accommodation, to the high price of clothing and other necessaries, particu- and passages are common, even in the best hotels, into which daylight never penetrates, and in which electric lights are necessary day and night.

Of course, conditions like these, which favour the dissemination of the tubercle bacilli, ought to be banished, but to revolutionize the domestic architecture and arrangements, as would be necessary, appears to be impracticable. There is about as much chance of this in Canada as of the extinction of poverty and the proper housing of the poor in this country.

This consideration gives to measures for preventing the dissemination of the tubercle bacilli primary and predominant importance, and it is the special merit of this little hospital that its purpose is to meet this requirement.

In dealing with consumption there are two distinct objects to be kept in view-the relief and cure of those already affected and the protection of the community generally from the disease.

In order that any sufficient degree of success may attend the first of these objects, the cases must be taken in hand at an early stage. It is on their behalf that sanatoriums have been erected for the open-air treatment, and it has almost come to be thought that these sanatoriums are the chief means to be relied upon for the suppression of consumption. They are, indeed, of very great impor-

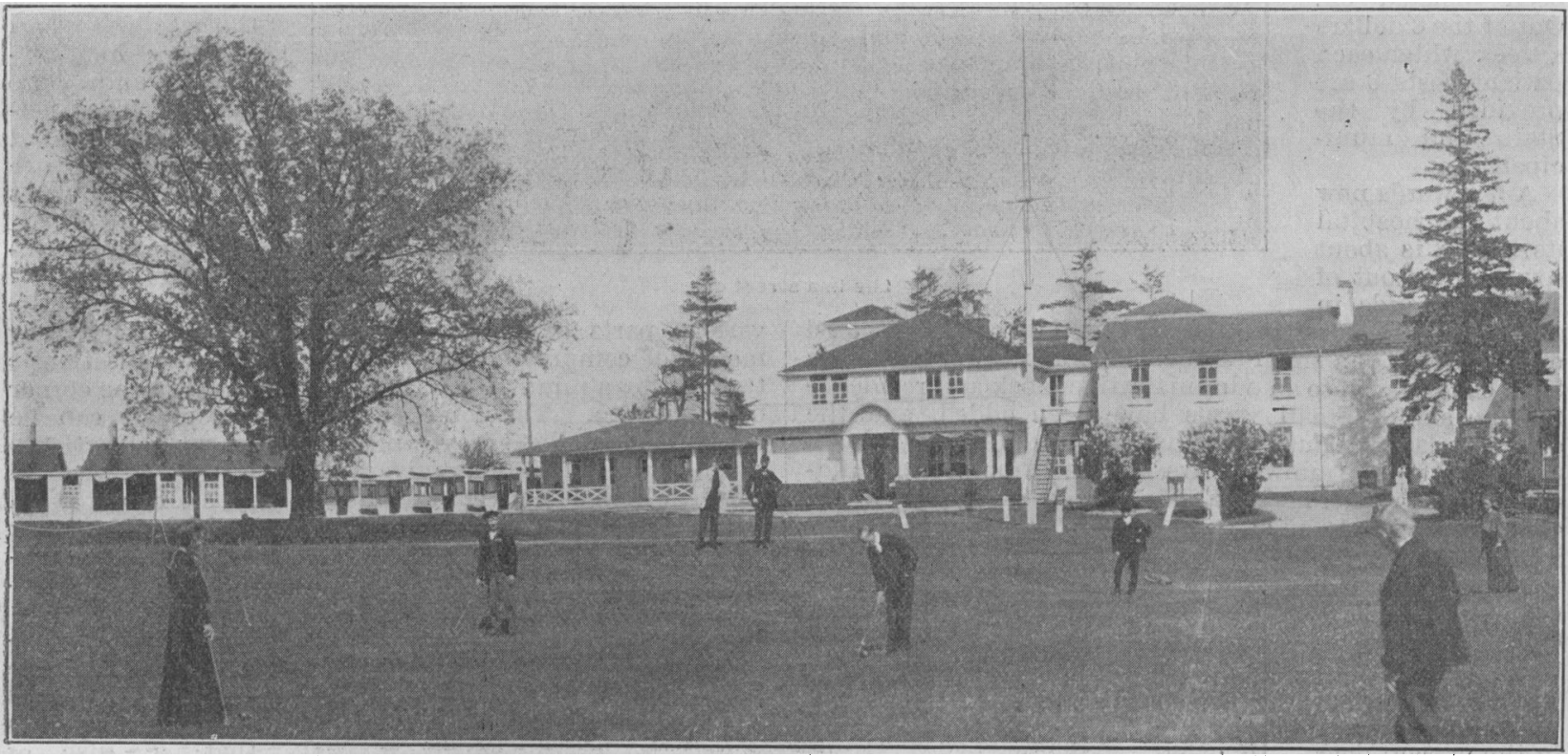

VIew of main bulldings, pavillon, and street-car shacks.

larly, perhaps, of coal as a defence against the long, cold winter, even of food which is produced so abundantly. Absolute poverty is almost unknown, except as a result of alcoholism and vice, and there seems to be ample provision against the impoverishing effects of sickhess and misfortune. Destitution cannot, therefore, be the main cause of consumption in Canada, or hold the same prominence in its leausation as in England and Europe generally.

A factor of very great importance is the method of heating dwelling-houses, which seems to be almost universally employed, at any rate in the towns. The abundance of wood would lead one to look for the large open fireplaces seen in old English houses; coal, too, is found in enormous quantity, but no doubt the distances, the want of means of communication, and the cost of labour make fuel expensive. The defence against cold, therefore, is to shut up houses and keep out the cold air; and to maintain a rather high temperature by means of radiators. Ventilation is reduced to a minimum; there is no compulsory influx of air by doors and.windows to replace that which goes up the chimney of an open fireplace-no automatic renewal of air, which is thus rebreathed over and over again, charged with moisture and impurities from the lungs and skin, so that the dwellings are, if not actually culture media for the tubercle bacillus, perfectly adapted to protect it from adverse influences and promote its virulence. Corridors ig tance in the combat against tuberculosis, since every case arrested ceases to be a focus of contagion, but the realization of the value and efficiency of the open-air treatment was an accidental coincidence with the discovery of the tubercle bacillus and the general recognition of the part it plays in the spread of the disease.

It is : in advanced and far-advanced cases that the tuberculous microbes are produced in dangerous, amount the copious expectoration teems with them. For the purpose of prevention the most important measure is the destruction of the sputum. Could this be effected completely the disease would be intercepted at its source, and in proportion as the expectoration is destroyed its spread is hindered and the community is protected from its ravages. If the expectoration is to be at all dealt with the sufferers must be under efficient supervision and control. In some instances such control might be exercised at home, but in an enormous majority of the cases removal from unfavourable surroundings and segregation in special hospitals will be imperative.

Of the two objects, the treatment of early cases and the isolation of advanced cases, by far the most important in the interests of the public is the latter. The provision for these two objects again falls on different shoulders. Sanatoriums for the treatment of presumably curable cases are a legitimate object for charitable effort. Hospitals for isolation purposes ought to be provided by the health arthorities. It in as muoh the duty of the bodies 
charged with the responsibility of guarding the public health to prevent the dissemination of tubercle bacilli in the air as to prevent the contamination of drinking water by typhoid bacilli.

The hospital for advanced and far-advanced consumption in Toronto is the first which, so far as I am aware, has been erected purely and simply with a view to prevention.* I do not

know who is to be credited with the idea, whether lay or medical, but I regard it as a fine instance of Canadian common sense and foresight. Its realization is due to Mr. Gage, Chairman of the Board of Management. It is all the more noteworthy as an example from the fact that the duty of municipal and State support has been insisted on. Out of the 8 dollars a week which each patient costs 6 are provided by the State and municipality.

A few words now about the hospital itself. It is about seven miles out of Toronto, stands in about forty acres of ground, and is pleasantly situated
near the edge of a small ravine. A pre-existing house has been converted into an administrative block and residence for the staff. Small wards have been added, and the accommodation thus furnished is supplemented by a number of old tramway cars grouped around the building, each of which makes a comfortable room with a bed and a few simple articles of furniture. In one corner is a small stove for winter weather. Tl: $\mathrm{e}$ number of beds is 66 , and, thanks to the simplicity of the arrangements, the total cost up to the present does not greatly exceed 40,000 dollars, very little over $£ 100$ a bed, the purchase of the land in. cluded. It is contemplated to build small wards for paying patients far advanced in consumption. The hospital is conducted on open-air principles, and is bright and cheerfu]. 'Three women sleps on a balcony all through last winter. A detail of some interest and importance is that the beds are not close up to the

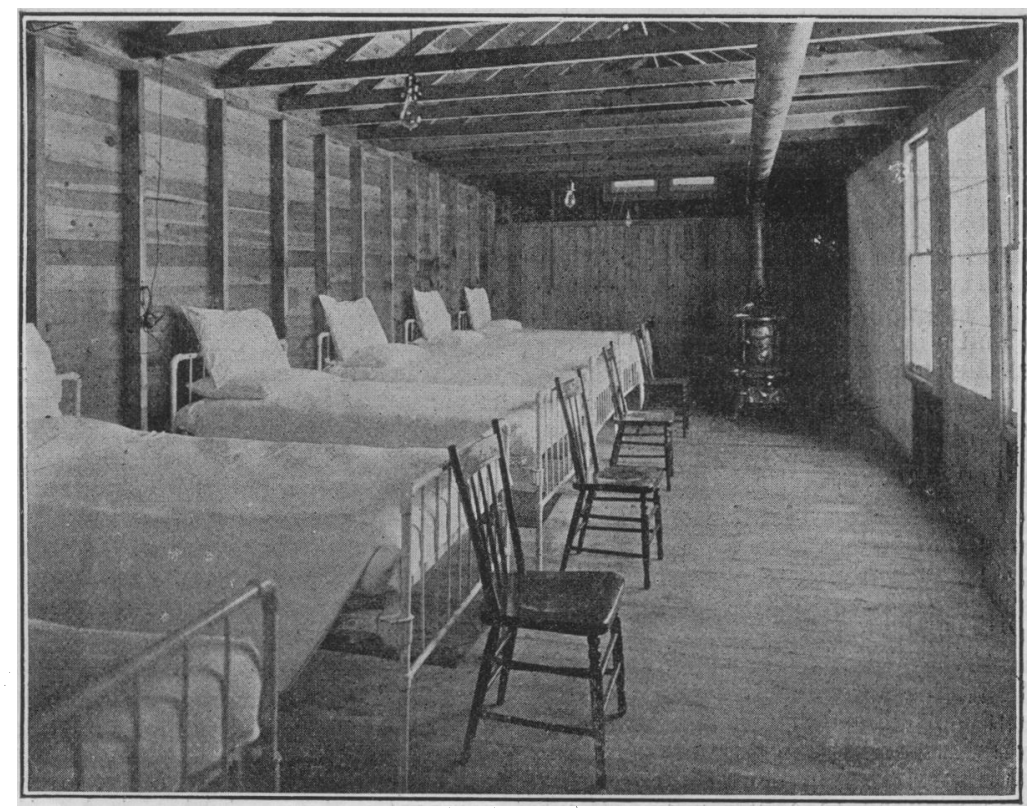

Interlor of tent cottage. duster is an excellent idea. The spittoons are small, square, flat tin boxes with a handle, within which is a closefitting box of stiff moisture-proof paper. They are all numbered, the paper and tin corresponding. The inner paper box is removed at regular intervals, and a note is taken of the amount and character of the contents, perhaps a specimen of the sputum withdrawn for

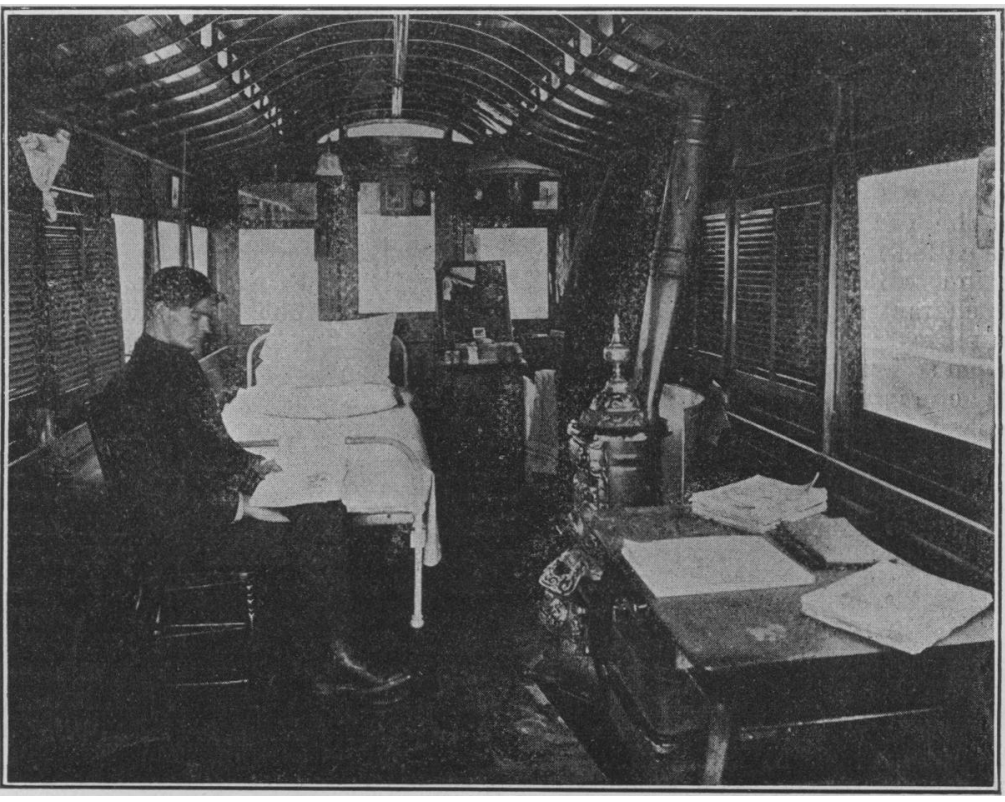

Ife in a street car examination, after which the paper box and its contents are burnt, The examination of the expectoration is facilitated, and there is no need for an elaborate apparatus for disinfecting the spittoons. The handkerchiefs are made of a soft thin cotton fabric called, I think, butter cloth, and are cut off from the piece in the institution. They cost less than the washing of an ordinary handkerchief, and are burnt. The administration and organization are evidently most efficient.

Spray and pulverized liquids and powders for the various parts of the air passages are administered by means of compressed air, operated, as the Transatlantic term is, by a minute electric motor situated in the corner of the room. The force of the current of air can be regulated, and the spray can be given to several patients. at once under the supervision of the resident medicap officer, which is a great advantage; they sit in a row on a form, each holding his own particular phial of inhalant into which the compressed air is conveyed.

Another interesting detail in the examination and operation room is that a disc of glass is suspended between the physician and patient during throat examinations. It prevents the disagreeable and dangerous projection of particles of expectoration into the examiner's face, which often gives rise to a suspension of the examination or operation, and it does not interfere with manipulations or with a good view of the mirror.

The value of a hospital like this is not measured by walls. If dust accumulates anywhere in a hospital ward | statistical results, but surprising improvement often takes or ordinary bedroom, it is under the head of the bed, place in the worst cases, and many patients have so far
and a clear space here easily accessible to the moist
recovered as to be fit to return to their homes without and a clear space here easily accessible to the moist

* I fear I am doing an injustice to the Royal Victoria Hospital, Edinburgh, where, under the inspiration of Dr. Philip, a pioneer in the campaign against tuberculosis, 50 beds are set apart for advanced cases. danger to their families.

Workhouse infirmaries have to a certain extent taken the place of such hospitals, and exercise their functions of segregating and isolating advanced cases but in a 
casual manner only. The protection of the public would be far more efficient were the purpose of this isolation iully recognized.

\section{A Clintiral lenture}

\section{, A RETROSPECT OF A THOUSAND CONSECUTIVE CASES OF ABDOMINAL SURGERY.}

By JAMES SWAIN, M.S., M.D.Lond., F.R.C.S.Eng., PROFESSOR OF SURGRRY IN UNIVERSITY COILEGE, BRISTOI;
SURGEON, BRISTOL ROYAL INFIRMARY.

In the haste of modern life there is a danger of finding little time to read and less to think; yet it behoves us to review periodically our methods, or we may fall behind the progress of the age and deceive ourselves with a false sense of efficiency.

Although abdominal surgery covers a wide field, there is little room for "specialism," for the surgeon who opens an abdomen should be prepared to treat whatever condition he may find present; and you may gather some idea of the nature and frequency of the various conditions more commonly met with when you know that my. series of cases includes 101 operations on the ovaries and tubes, 75 on the uterus and broad ligaments, 127 operations for hernia, 229 for appendicitis, 49 operations for diseases of the liver, gall bladder, and bile ducts, 65 operations on the kidney, 126 operations for diseases of the stomach and intestines (excluding hernia and appendicitis), 29 operations on the urinary bladder and prostate, and 24 operations for tuberculous peritonitis and peritoneal adhesions.

We can analyse these figures when speaking of some of these operations later, but there are certain general considerations which must first be discussed, though it should be borne in mind that I am dealing solely with such methods as I have thought it best to adopt, and I do not propose to give you an account of the many ways and means that others may prefer.

It must be remembered that the chief source of infection of wounds is the skin of the operator and his assistants on the one hand and that of the patient on the other; and as all methods of disinfection are easily likely to fail, it is desirable that great attention should be given to this point. The hands should be scrubbed with a sterile nailbrush for five minutes in frequent changes of hot. water and soap, and afterwards immersed for at least two minutes in a 1 in 500 solution of biniodide of mercury, with 70 per cent. alcohol, as recommended by Lockwood, This solution can be allowed to dry on the hands, or a dry sterile cloth can be used, and rubber gloves (previously sterilized) are then put on. It is true that rubber gloves diminish tactile sense, but the feeling of security' and the additional safeguard against sepsis which they furnish more than counterbalance the slight inconvenience entailed by their use. The skin of the patient is often prepared some hours before operation. After being shaved, it is treated with turpentine, ether, and soap and water, and then covered with a weak antiseptic dressing; but, just before operation, it should be covered with a cloth wet with the alcoholic biniodide solution already referred to. As soon as the incision in the skin is made, a further protection against the possibility of infection from the skin of the patient is afforded by clipping the edge of a large sheet (which covers the patient except for a hole opposite the operation area) to the sides of the wound.

Consistently with freedom of manipulation, all abdominal incisions should be as short as possible-in appendicitis it is rarely necessary for it to extend much above 2 in. in length. In operating on the lateral parts of the abdomen, where the incision goes through a muscular area, the method of McBurney, in which the muscular fibres are separated bluntly and not divided, should always be adopted if possible. If this form of incision is used in cases of appendicitis, ventral hernia can scarcely follow, provided that no suppuration occurs. In operating in the middle line the tissues are best divided by raising them on two pairs of forceps, and cutting between them. The interval between the two recti is sought-one or other sheath being ofened-and the peritoneum then incised between two forceps, as already mentioned. McBurney's incision is closed in layers; but incisions in the mid-line are closed by stitches of silkworm gut, taking in all the tissues on either side, and supplemented by a few superficial intervening stitches for the more complete approximation of the skin. I do not believe it to be necessary to adopt any of the more recent complicated incisions for opening the abdomen in or near the mid-line, nor do I think it necessary, as a rule, to suture such wounds in layers. The prevention of ventral hernia following abdominal incisions is best secured by keeping the incision as short as possible, avoiding undue tension on the stitches, and by the attainment of union by "first intention." If these conditions obtain, it matters little what form of incision or suturing is adopted; and in support of the efficiency of the simple methods suggested it may be noted that in the period covered by this series of cases there were only seven operations for ventral herniae of all kinds, including those that followed suppurative appendicitis and other conditions which are known to favour the occurrence of hernia.

Marine sponges have been discarded in favour of swabs of dry sterile gauze, but no swab is placed in the abdominal cavity unless it has a long tape attached to it in order that it may be easily found and removed.

Boiled silk or cellulose thread is used inside the peritoneal cavity, the former for the suture of intestine, the latter for ligatures of vessels, etc. The finest cellulose thread is not fine enough for intestinal work, though it bears boiling better and is less bulky than silk for other purposes. Catgut, though theoretically better, is less reliable.

Irrigation of the abdomen has been practically abandoned except in some cases of ruptured intestine, perforated gastric ulcer, or other condition leading to extensive fouling of the peritoneum. When resorted to, the incisions should be free, so that the process may be thoroughly carried out in all parts of the abdominal cavity; and, if necessary for this purpose, the intestines should be turned out into warm cloths. Unless done with assiduous care, irrigation may be productive of more harm than good, and I well remember cases of suppurative appendicitis that were lost when "flushing the abdomen" was in vogue, that might have been saved by the adoption of the present treatment of dry sponging.

In non-suppurative cases, just before the last stitch is tied at the end of the operation, I frequently put two or three pints of hot normal saline solution into the abdomen, and leave it there to be absorbed. It certainly prevents much of the thirst from which most cases of abdominal operation suffer, and I am inclined to think it diminishes pain.

Superficial (skin) stitches are removed at the end of a week, but deep stitches are left for a fortnight or longer. In all cases where the incision has been more than 2 in. in length, the patient is advised to wear an abdominal belt and pad for six months to a year.

The discussion of the diagnosis of abdominal diseases is too extensive for my present purpose ; but before dealing with the different groups of operations I should like to remind you that many acute abdominal conditions commence in much the same way, and thus may lead to some difficulty in diagnosis at the beginning of the mischief. Thus, vomiting in association with pain and collapse is found in almost every case of acute abdominal crisis, whatever the cause of the attack may beappendicitis, perforated gastric ulcer, a twisted ovarian pedicle, and numerous other conditions, are all characterized in the early stage by this triad of symptoms, for which Treves suggested the term "peritonism." Under such circumstances, however, we have not to wait long, as a rule, before the localization of pain and tenderness lead to a sufficient diagnosis of the case for the purposes of treatment. If the vomiting is produced by one of the many forms of intestinal obstruction, the retracted and rigid abdomen of the commencement of the attack is soon replaced by a gradually increasing abdominal distension; and the same is true of many cases of perforative peritonitis. It is not desirable to wait for this abdominal distension in cases where the diagnosis is clear; and I have always found it to be a safe surgical practice to open the abdomen without delay in cases of doubtful diagnosis where the vomiting is associated with a gradually 